\title{
ROTAS DE VINHO E DESENVOLVIMENTO REGIONAL
}

\author{
Eduardo C. Cordeiro Gonçalves \\ Instituto Superior da Maia - ISMAI (Portugal) \\ CEDTUR - Centro de Estudos de Desenvolvimento Turístico e CETRAD
}

Resumo: Vinho e turismo constituem hoje dois produtos cada vez mais complementares, mormente em regiões vitivinícolas deprimidas e que encetaram processos de restruturação com a introdução da componente turística. Estamos, assim, perante duas componentes determinadas a partir do contexto territorial, porquanto quer a regulamentação e certificação do vinho parte de pressupostos regionais - a região demarcada - e o turismo que se articula com o desenho e a atracção do destino - local ou regional - exercida sobre o turista. Esta associação do vinho ao turismo implica ainda a valorização da "marca" onde o ênfase regional vai contribuir, sobremaneira, para o desenvolvimento e a sustentabilidade da região.

Assim, o enoturismo representa actualmente mais do que uma motivação específica para a realização da viagem induzida pelo vinho, ele constitui uma nova oportunidade de negócio e um catalisador para a economia de uma região vitivinícola. A par, pode igualmente contribuir para o "afinar do destino turístico", pois passa a promover a região e um conjunto de actividades associadas ao vinho.

Por conseguinte, o sucesso de um destino enoturístico e o desenho das rotas vitícolas estão simultaneamente associados à reputação do vinho da região, à organização da adega e ao acolhimento dos visitantes, à dinamização e promoção dos elementos endógenos e do único, á criação de um conjunto de serviços, atracções e eventos que permitem complementar a adega e qualificar a região enquanto produto"turismo integrado numa matriz cultural.

Palavras-chave: Rotas de vinho; enoturismo; desenvolvimento regional.

\footnotetext{
Abstract: Wine routes and regional development

Wine and tourism are two products today increasingly complementary, especially in depressed and wine regions that have depressed upon restructuring with the introduction of tourism component. Moreover, these two components can be determined from the territorial context, because both the regulations and certification of the wine part of regional assumptions - the demarcated region - tourism and, in turn, is linked to the design and attractiveness of destination - local or regional - exerted on the tourist. This association of wine to tourism also implies the recognition of the "brand" where the regional emphasis will greatly contribute to the development and sustainability of the region.
} 
Thus, wine tourism currently represents more than a specific motivation for holding the wine driven trip, it is a new business opportunity and a catalyst for the economy of a wine region. At the same time, it can also contribute to "fine tune the tourist destination", as it starts to promote the region and a range of activities associated with wine.

Therefore, the success of a wine tourism destination and the design of wine routes are both associated with the reputation of the region's wine, the organization of the cellar and the reception of visitors, the stimulation and promotion of endogenous elements and of the "unique", will create a set of services, attractions and events that allow to complement the winery and to qualify the region as an integrated tourist product.

Keywords: Wine routes, wine tourism, regional development.

\section{Resumen: Rutas de vino y desarrollo regional}

Vino y turismo constituyen hoy dos productos cada vez más complementarios, especialmente en las regiones vitivinícolas deprimidas y que han emprendido procesos de reestructuración con la introducción del componente turístico. Además, estos dos componentes pueden ser determinados a partir del contexto territorial, por cuanto la regulación y la certificación del vino parte de presupuestos regionales -la región demarcada- y el turismo, a su vez, se articula con el diseño y el atractivo del destino -local o regional- ejercido sobre el turista. Esta asociación de vino y turismo implica el reconocimiento de la "marca", donde el énfasis regional contribuirá, en gran medida, al desarrollo y la sostenibilidad de la región.

Así, el enoturismo representa actualmente más que una motivación específica para la realización del viaje inducido por el vino, al constituir una nueva oportunidad de negocio y un catalizador para la economía de una región vitivinícola. Además, puede contribuir igualmente a "afinar el destino turístico", pues pasa a promover la región y un conjunto de actividades asociadas al vino.

Por consiguiente, el éxito de un destino enoturístico y el diseño de rutas vitícolas están simultáneamente asociados a la reputación del vino de la región, a la organización de la bodega y a la recepción de los visitantes, la dinamización y promoción de los elementos endógenos y de lo "único", la creación de un conjunto de servicios, atracciones y eventos que permitan complementar la bodega y calificar la región en cuanto producto turístico integrado.

Palabras clave: Rutas del vino, enoturismo, desarrollo regional.

1. Falar de rotas de vinho é falar igualmente de enoturismo. Vinho e turismo constituem dois produtos que se articulam, em regra, numa dimensão territorial, porquanto a regulamentação e a certificação do vinho é prosseguida numa base regional - a região demarcada -terroir - e o turismo está intimamente articulado com o desenho e a atracção do destino exercida sobre o turista (Brás, 2010: 57). Por conseguinte, esta associação do vinho ao turismo tem hoje cada vez maior relevância considerando a valorização e promoção da "marca" a par do ênfase regional, factores que contribuem, sobremaneira, para o desenvolvimento económico da região (Hall, 2000: 1-23).

$\mathrm{O}$ conceito associado ao enoturismo envolve, pois, a actividade turística que tem como lastro a viagem motivada pela cultura do vinho e da vinha, bem como pela tradição e pelo ethos local, imbricando aqui um conjunto de oportunidades em ordem á dinamização de redes e/ou Clusters, na medida em que se conjugam dois sectores de actividade distintos que, de per si, podem promover redes internas (Porter, 1998).

O produto associado ao enoturismo está, assim, plasmado em duas indústrias (a da viticultura e a do turismo) que extravasam as economias regionais e se alongam ao 
próprio estilo de vida e á comunidades anfitriã. Afigura-se também relevante a paisagem cultural da viticultura respaldada em valores patrimoniais e arquitectónicos complementares, bem como em valores ambientais e outros atinentes à atmosfera das vilas e aldeias, das Quintas, das edificações enobrecidas ou mesmo adegas mais modestas (Getz, 2000). As marcas tangíveis desta paisagem cultural são hoje acrescidas pela vontade do experiênciar por parte do enoturista, não só através do contacto com a história, mas também com a memória e a tradição vernacular, ou até com a gastronomia local, em suma, com o património cultural num sentido holístico.

Complementando a oferta da experiência, o enoturismo deve preservar uma perspectiva de autenticidade cultural (tradições, marcas etnográficas, eventos, aldeias e cidades do vinho), promover a festa e fomentar o conhecimento e formação e informação em torno do vinho - como se cultiva e produz; como se prova; que tipologias; que características (Hall: 1996; Getz: 2000).

Além dos motivos específicos que fundamentam a viagem enoturística é hoje assumida «como janela de oportunidade e de negócio» e uma mais-valia para a economia de uma região vitivinícola, porquanto ele tem os ingredientes que podem contribuir para o "afinar do destino turístico", na medida em que se passa a promover uma região e um conjunto de dinâmicas vitivinícolas associadas às Quintas, caves e adegas e vitivinicultores, mas também o alojamento, a restauração e as actividades de animação, por exemplo). De resto, o enoturimo constitui hoje o dito core business de muitas Quintas e adegas, mormente para as de menor dimensão que produzem os seus vinhos numa envolvente familiar e/ou de opção de vida (Brás, 2010: 62-63). Para outras, o enoturismo representa um complemento ao negócio principal - a produção de vinho -, assumindo, porém, um significado promocional e comercial para os seus vinhos.

A aposta no enoturismo revela, em regra, o posicionamento de cada adega face ao negócio, a um tempo como "um complemento" e "um meio de promoção e de marketing" dos seus produtos, sendo que a visita às caves vai funcionar como catalisador da própria actividade (Dod, 1995). Como sublinha T. Dodd, as dinâmicas enoturísticas dos produtores, Quintas e adegas estão patentes na:

i) A oportunidade de mostrar os produtos aos visitantes e promoção do vinho da Quinta e/ou adega;

ii) A interacção com o visitante na Quinta/adega permite que se fomentem laços entre ambos que podem potenciar a fidelização do visitante ao vinho e à sua marca;

iii) Esse contacto permite, ainda, a percepção das preferências e expectativas, assim como a análise da reacção do visitante a cada vinho ou produto, proporcionando a implementação do designado marketing relacional (Dodd, 1995: 53).

A experiência proporcionada pelo enoturismo, mormente no que concerne ao conhecimento e ao contacto com os processos vitícolas e com os produtores, assume-se como um dos factores determinantes para o seu futuro. Conhecer as características dos visitantes e as suas motivações permite apoiar a definição de estratégias de desenvolvi- 
mento e de marketing com o fim de potenciar o êxito do projecto através do aumento do número de visitantes e do desejável aumento do volume de negócios (Getz, 2000).

Contributo do enoturismo para a região vitivinícola

\begin{tabular}{|c|c|c|}
\hline Na vitivinicultura & No destino enoturístico & Na comunidade anfitriã \\
\hline $\begin{array}{l}\text { - Aumento do volume de } \\
\text { vendas de vinho } \\
\text { - Aumento da amplitude } \\
\text { das mais-valias } \\
\text { - Fidelidade à marca } \\
\text { - Melhor articulação en- } \\
\text { tre produtor e engarra- } \\
\text { fador } \\
\text { - Incremento de parce- } \\
\text { rias } \\
\text { - Desenvolvimento de } \\
\text { novos produtos }\end{array}$ & $\begin{array}{l}\text { - Mais visitantes } \\
\text { - Aumento do número de } \\
\text { visitantes } \\
\text { - Fidelização dos visi- } \\
\text { tantes } \\
\text { - Potenciar a divulgação } \\
\text { de uma imagem inte- } \\
\text { grada } \\
\text { - Travar a sazonalidade }\end{array}$ & $\begin{array}{l}\text { - Atracção de investimen- } \\
\text { to } \\
\text { - Redimensionação de } \\
\text { equipamentos e infra- } \\
\text { estruturas } \\
\text { - Promoção de identida- } \\
\text { des regionais } \\
\text { - Organização de eventos } \\
\text { que envolvam os visi- } \\
\text { tantes e as comunidades } \\
\text { anfitriãs }\end{array}$ \\
\hline
\end{tabular}

Fonte: Getz, 2000; adaptado.

Actualmente, vinho e gastronomia conjugados afirmam-se também como elementos da cultura tradicional regional e são cada vez mais indissociáveis quer na óptica da gastronomia e cultura, quer numa perspectiva de experimentação - a dita nouvelle cuisine que radica do estímulo dos sentidos e propõe uma leitura dos alimentos.

Por outro lado, o enoturismo conjuga-se e pode inserir-se nos conceitos de Turismo Rural, de Turismo de Natureza e de Turismo Cultural (Brás, 2010: 67). Há casos, porém, que o enoturismo pode ocorrer no espaço urbano, na medida em que algumas caves, adegas, feiras, festivais e eventos do vinho e da vinha ocorrem estrategicamente em espaços urbanos, ainda que urbano e rural se mostrem complementares, veja-se o caso da complementaridade entre o Porto e o Douro. É, pois, daquele mosaico de motivações e serviços transversais que pode resultar o sucesso do enoturismo em cada região vitivinícola.

Em Portugal o enoturismo assume diversas feições articuladas com as regiões vitivinícolas, tendo sido criadas nesse contexto rotas vitícolas, promovidas inicialmente pelo ICEP - Instituto do Comércio Externo de Portugal - e pelos agentes que nelas participam e/ou as integram. De resto, o enoturismoestá incluído no PENT - Plano Nacional Estratégico de Turismo, apresentado na Bolsa de Turismo de Lisboa (BTL), em 2006, como um dos 10 produtos prioritários a desenvolver no âmbito da actividade turística de Portugal sob a designação de "Gastronomia e Vinho" (Pent, 2006: 63).

2. Ora, como ficou dito, de entre as várias formas de intersecção entre a vitivinicultura e o desenvolvimento de outras actividades alternativas á dependência da monocultura destaca-se o aproveitamento turístico das paisagens vitícolas e dos processos tecnológicos vinários no âmbito das rotas do vinho (Simões: 1998). 
Recorde-se que as rotas do vinho existem na Europa há mais de 50 anos e revelam-se nodais para a implementação de estratégias de enoturismo, porquanto oferecem uma oportunidade para cada região tornar tangível a temática do vinho. O Conselho Europeu de Rotas de Vinho (CERV) constitui uma "rede de cooperação inter-regional e agrupa instituições públicas e privadas, regionais e locais" (Brás, 2010: 74) dedicada ao turismo vitivinícola. Este Conselho considera que para lá da relevância económica e concomitantemente social, o enoturismo deve ser entendido também como um modo de divulgação e promoção do património cultural. Tendo, assim, em vista aquele desiderato e a sua articulação com a implementação de rotas de vinho, o mesmo organismo desenvolveu um "guia metodológico" para a elaboração destas rotas.

As rotas do vinho começam a ser delineadas em Portugal nos inícios dos anos de 1990, coincidindo com inclusão no programa Dyonisios divulgado pela União Europeia. Tendo por base as Comissões Vitivinícolas Regionais, parte das rotas de vinho organizaram-se entre 1996 e 1998, propondo incrementar o potencial turístico de cada uma das regiões em causa. Com efeito, cada rota integra um conjunto de locais, empresas e organismos com potencial turístico, "estruturados e sinalizados em rede" (Orlando, 2008: 275).

A par, o Instituto da Vinha e do Vinho (IVV), sob a tutela do Ministério da Agricultura, considera que o principal objectivo das rotas de vinho é promover o "turismo vitivinícola", sendo que este possibilita ao visitante o contacto directo com as novas ruralidades e a sua cultura contribuindo para a preservação da autenticidade e do diferenciador de cada região através da divulgação do seu artesanato, do património paisagístico, arquitectónico e museológico, da gastronomia local, contrariando o processo de depressão e constrangimento económico evidenciado em muitas zonas rurais (Reis,2012).

Com o desenvolvimento destas rotas os visitantes beneficiam de mais informação e melhores acessibilidades aos recursos. Assim, tal como vinho e turismo são dois produtos diferenciados numa base regional, a noção de rota de vinho é igualmente entendida como instrumento de "desenvolvimento territorial" visando a internacionalização assente na qualificação das actividades ligadas à vitivinicultura (Brás, 2010). As rotas de vinho são consideradas um factor de inovação no âmbito da economia global, não deixando, todavia, de contribuir para a qualidade dos sistemas vitivinícolas e de se assumirem como uma estrutura de coordenação de uma rede territorial (Vandecandelaere, 2003).

Por sua vez, a tipologia de aderentes é diversificada, contando-se nesse universo adegas cooperativas e as suas uniões, associação de viticultores-engarrafadores, mas também armazenistas, museus, casas de Turismo em Espaço Rural e outros núcleos de interesse vitivinícola. Os casos mais frequentes de integração concernem a unidades agrícolas de grande extensão, cujas designações variam consoante as regiões e o tipo de habitação que a caracterizam, tal o caso de quintas, casais, casas agrícolas, paços e solares. Outro dos aderentes com relevância para o projecto de afirmação da rota são as adegas cooperativas e respectivas uniões, com especial incidência nas rotas do Dão, Alentejo e do Vinho do Porto. Seguem-se os armazenistas com um peso mais vincado na rota da Bairrada onde se destacam as suas conhecidas caves (Orlando, 2008: 275). 
Porém, não existem diferenças claras entre as diversas rotas no que diz respeito ao tipo de ofertas disponibilizadas. Com a excepção da Rota do Vinho do Porto, que privilegia a prova e a venda de vinhos em detrimento das visitas ás vinhas e adegas, todas as outras rotas mostram um perfil de oferta similar. Praticamente todos os aderentes oferecem prova e venda de vinhos e visita às adegas. Nessa programação é ainda considera a visita às vinhas, a visita aos museus e a prática de o Turismo em Espaço Rural. De resto, o caso emblemático do Douro beneficia de um desenvolvimento agrícola e turístico em paralelo, que resulta na valorização da região de modo singular derivado da sua complementaridade. Defende-se, pois, a existência de um valor acrescentado que deriva desta exploração de diversidade de práticas turísticas de qualidade mas também agrícolas e que é nitidamente superior à somatória do valor de cada uma delas isoladamente (Costa \& Kastenholz: 2009). São muitos os exemplos na região duriense da aplicação dessa complementaridade, os casos da Quinta do Vallado, da Quinta de La Rosa, da Quinta do Portal, da Quinta do Passadouro, da Quinta Vale Dona Maria, da Quinta de Sat ${ }^{\circ}$ António de Adorigo, da Quinta da Pacheca ou da Quinta de Nossa Senhora do Carmo, só para citar algumas.

Em qualquer dos casos, o que se ressalva destes exemplos é, por um lado, o seguimento da vanguarda das tendências turísticas em termos globais, onde o casamento entre tradição e modernidade está omnipresente. Por outro lado, salienta-se o facto de se ficar a dever à iniciativa privada a forte dinâmica de revitalização do sector.

3. Numa óptica de desenvolvimento prospectivo é possível enunciar dois tipos de associações: i) Dentro da mesma actividade (turismo ou vinho); ii) Entre os dois sectores de actividade - turismo e vinho - podendo estas associações serem complementadas através de processos de integração horizontal ou vertical. Assim, a fase inicial de envolvimento dessa associação pode passar pela existência de um itinerário sinalizado ao longo de uma área limitada, o caso da região demarcada, como objectivo de mostrar as actividades e produtos associados ao vinho patentes na região (Brás, 2012).

Estruturar uma rota de vinho gera também a formulação de uma rede de natureza económica e, consequentemente, social, matizada por uma flexibilidade capaz de oferecer um conjunto diverso de produtos e de proporcionar uma "economia de escala" que gerará um previsível incremento de externalidades positivas da rede, incitando à aquisição de competências e à transmissão de conhecimento colectivo. Partindo de determinada organização e da estratégia adoptada, focada num único produto ou envolvendo uma diversidade de produtos e serviços, é possível definir distintos tipos de rotas de vinho, a saber:

- Rota de Marca - Corresponde à ligação em rede de um conjunto de pontos de venda de vinho entre um conjunto fechado de aderentes;

- Rota de Marca Regional - Que deriva da vontade de instituições regionais se associarem aos agentes do sector vitivinícola, não limitando a adesão de novos aderentes, embora não interaja com outros sectores de actividade; 
- Rota de Terroir - Combina relações importantes entre os diferentes agentes do território e considera os requisitos do terroir como condição para a aceitação de novos aderentes;

- Rota Territorial - Pretende promover o maior número de agentes locais inseridos no território e fomenta o voluntarismo dos agentes, reduzindo entraves à adesão de novos agentes; Visa, pois, proporcionar uma oferta diversificada baseada na cooperação dos diversos agentes (Vandecandelaer e Touzard, 2003; Brás, 2010).

Ora, as regiões vitivinícolas podem apresentar-se enquanto destinos integrado através da inclusão das diferentes componentes do produto, associando as principais atracções que vão do vinho e gastronomia ao alojamento e á animação, a par de uma gama diversificada de serviços tidos como essenciais para potenciar o turismo na região. Oferta regional e qualificação dos recursos de modo sistematizado não é despicienda para o aprofundar de segmentos de mercado de gama alta e com maior poder de compra, sendo este um tipo de gestão que permite complementarmente o controlo de um não desejável turismo de massas e do efeito da sazonalidade. O sucesso de um destino enoturistico está, assim, associado à reputação do vinho da região, à organização da adega e acolhimento do visitante, à dinamização e promoção dos elementos endógenos, á criação de um conjunto de serviços, atracões eventos que permitam complementar a adega e qualificar a região enquanto produto turístico integrado, qualidade das acessibilidades, liderança e organização da região no contexto do seu processo de desenvolvimento e as sinergias proporcionadas pelo cruzamento entre o vinho e as sociabilidades locais.

\section{CONCLUINDO:}

A implementação de uma rota de vinho deve ser dinâmica e conjugar-se com o conjunto de recursos proporcionados pelos agentes regionais conjugados, sendo que os visitantes deveram ter a possibilidade de cerzir o seu próprio itinerário, porquanto deverão poder escolher os pontos de interesse e os recursos associados que entenderem.

Porém, a construção de uma rota implica procedimentos de inventariação de recursos regionais e a identificação das características endógenas a ser disponibilizadas na escolha aleatória pelos visitantes em função das suas motivações, diligências que levarão á construção de um backoffice preliminar.

A conjugação das opções pretendidas possibilita o "sentido da descoberta durante a visita" que deverá proporcionar uma experiência gratificante para o visitante, considerando que o objectivo passa por lhe facultar uma gestão personalizada da visita à região, isto usando a rota e a selecção do seu caminho em função de um conjunto de recursos e de uma experiência única. Por conseguinte, o conceito que deve presidir ao desenvolvimento de rotas evidencia uma evolução em ordem a uma maior flexibilidade e adaptabilidade em contraponto a um conceito cristalizado de rota. 
Considerando-se a relevância da selecção das preferências, dos gostos e das motivações do mercado poderemos antecipar a adequação da oferta à procura. Daí, como sublinham os estudos de Dimitrios Buhalis, a influência cada vez maior da utilização das comunidades virtuais dinamizadas em ambiente web para o mercado, quer pelos inputs que dá a cada um dos destinos a nível da definição de estratégias de marketing quer pela influência que geram em potenciais visitantes pela via da partilha e do experienciado.

Mas, para além do mais, como forma de aumentar a competitividade de determinada região, é necessário produzir e divulgar conhecimento sobre a mesma, de modo a ser aproveitado pelos agentes económicos e e de gestão territorial para a elaboração de novas estratégias competitivas. Este conhecimento deve ser de natureza técnico-económica, no que á competitividade sectorial diz respeito, mas também de natureza territorial, ligando a sua simbologia à de região produtora de vinho e á formulação de conhecimento sobre a história da região, sobre a sua cultura e as suas especificidades.

\section{BIBLIOGRAFIA}

Brás, José M. (2010): As rotas de vinho como elementos de desenvolvimento económico, Aveiro, UA.

Buhalis, Dimítrios; Schertler, W., eds. (1999): Information and communication technologies in tourism, Viena/New York: Springer.

Costa, Adriano e Kastenholz (2009): "O enoturismo como factor de desenvolvimento das regiões mais desfavorecidas", $2^{\circ}$ Congresso Lusófono de Ciência Regional, Cabo Verde, Redes de Desenvolvimento Regional, p.1489-1508.

Dodd, T. H. (1995): “Opportunitiesandpitfallsof touris min a developingwineindustry", InternationalJournalofWine Marketing. 7(1): 5-17.

Getz, D. (2000): Explore winetourism, manegement, development\&destinations, New Yorke, CognizantCommunicationsCorporation.

Hall, C. M. etalli. (2000): "WineTourism: anintrodution", Hall, C. M.; Sharples, E., Wine Tourism around the world, Oxford, Butterworth-Heinemann, pp.1-23.

Hjalager, A. \&Richards, G. (Eds.) (2002): Tourismandgastronomy, Oxon, Routledge.

Inácio, Ana Isabel (2007): “O enoturismo: da tradição à inovação, uma forma de desenvolvimento rural", Actas do III Congresso de Estudos Rurais, Faro, Universidade do Algarve, pp.1-16.

Porter, M E. (1998): "Cluster and the new economics of competitions", Harvard Business Review, 76 (6): 77-90.

Reis, Paula (2012): Desenvolvimento local: o binómio turismo/áreas rurais nas estratégias de desenvolvimento local, Coimbra, Escola Superior de Educação de Coimbra.

Simões, Orlando (1998): A economia do vinho no século XX: Crises e regulação, Lisboa, Universidade Técnica de Lisboa. 
Simões, Orlando (2008): "Enoturismo em Portugal”, PASOS: Revista de Turismo y Património Cultural, La Laguna, 6 (9): 269-279. 